\title{
Current Antimalarial Therapies and Advances in the Development of Semi-Synthetic Artemisinin Derivatives
}

\author{
LUIZ C.S. PINHEIRO ${ }^{1}$, LÍVIA M. FEITOSA ${ }^{1,2}$, FLÁVIA F. DA SILVEIRA ${ }^{1,2}$ and NUBIA BOECHAT ${ }^{1}$ \\ ${ }^{1}$ Fundação Oswaldo Cruz, Instituto de Tecnologia em Fármacos Farmanguinhos, Fiocruz, Departamento de \\ Síntese de Fármacos, Rua Sizenando Nabuco, 100, Manguinhos, 21041-250 Rio de Janeiro, RJ, Brazil \\ ${ }^{2}$ Universidade Federal do Rio de Janeiro, Programa de Pós-Graduação em Química, Avenida Athos \\ da Silveira Ramos, 149, Cidade Universitária, 21941-909 Rio de Janeiro, RJ, Brazil
}

Manuscript received on October 17, 2017; accepted for publication on December 18, 2017

\begin{abstract}
According to the World Health Organization, malaria remains one of the biggest public health problems in the world. The development of resistance is a current concern, mainly because the number of safe drugs for this disease is limited. Artemisinin-based combination therapy is recommended by the World Health Organization to prevent or delay the onset of resistance. Thus, the need to obtain new drugs makes artemisinin the most widely used scaffold to obtain synthetic compounds. This review describes the drugs based on artemisinin and its derivatives, including hybrid derivatives and dimers, trimers and tetramers that contain an endoperoxide bridge. This class of compounds is of extreme importance for the discovery of new drugs to treat malaria.
\end{abstract}

Key words: malaria, Plasmodium falciparum, artemisinin, hybrid.

Abbreviations:

amodiaquine - AQ

artemisinin - ART

artemisinin-based combination therapy - ACT

chloroquine - CQ

chloroquine-resistant - CQR

dihydroartemisinin - DHA

dihydrofolate reductase - DHFR

dihydropteroate synthase - DHPS

Drugs Initiative for Neglected Diseases - DNDi

European Medicines Agency - EMA

Correspondence to: Nubia Boechat

E-mail: nubia.boechat@far.fiocruz.br

* Contribution to the centenary of the Brazilian Academy of Sciences. fixed-dose combination - FDC

Medicines for Malaria Venture - MMV

mefloquine - MQ

$p$-aminobenzoic acid - PABA

pharmaceutical fixed-dose combination - FDC

Plasmodium falciparum - P. falciparum

Plasmodium knowlesi - P. knowlesi

Plasmodium malariae - P. malariae,

Plasmodium ovale - P. ovale

Plasmodium vivax - P. vivax,

primaquine - PQ

pyronaridine - PYR

quinine - QN

World Health Organization - WHO 


\section{INTRODUCTION}

Malaria is one of the most important public health problems worldwide, with almost half of the global population exposed to the risk of contamination. This disease is present in 91 countries, mostly in tropical and subtropical regions of the planet. However, due to globalization, the incidence of malaria has been alarming in virtually all countries, given that malaria cases are increasing in firstworld countries. In 2016, it was estimated using data from the World Health Organization (WHO) that there were 212 million malaria cases in the world, leading to 429,000 deaths, mainly in African countries, among children under 5 years of age (WHO 2016).

Malaria is caused by single-celled protozoa of the genus Plasmodium and is considered a severe, infectious, parasitic disease. This disease is transmitted by the bite of the female mosquito of the genus Anopheles infected with the protozoa, of which five species are responsible for infecting humans: Plasmodium falciparum, $P$. vivax, $P$. malariae, P. ovale and P. knowlesi (Garcia 2010).

The life cycle of Plasmodium species (Figure 1 ) is divided into different phases and between two hosts: a vertebrate and the mosquito. The onset of infection occurs with the bite of an infected female
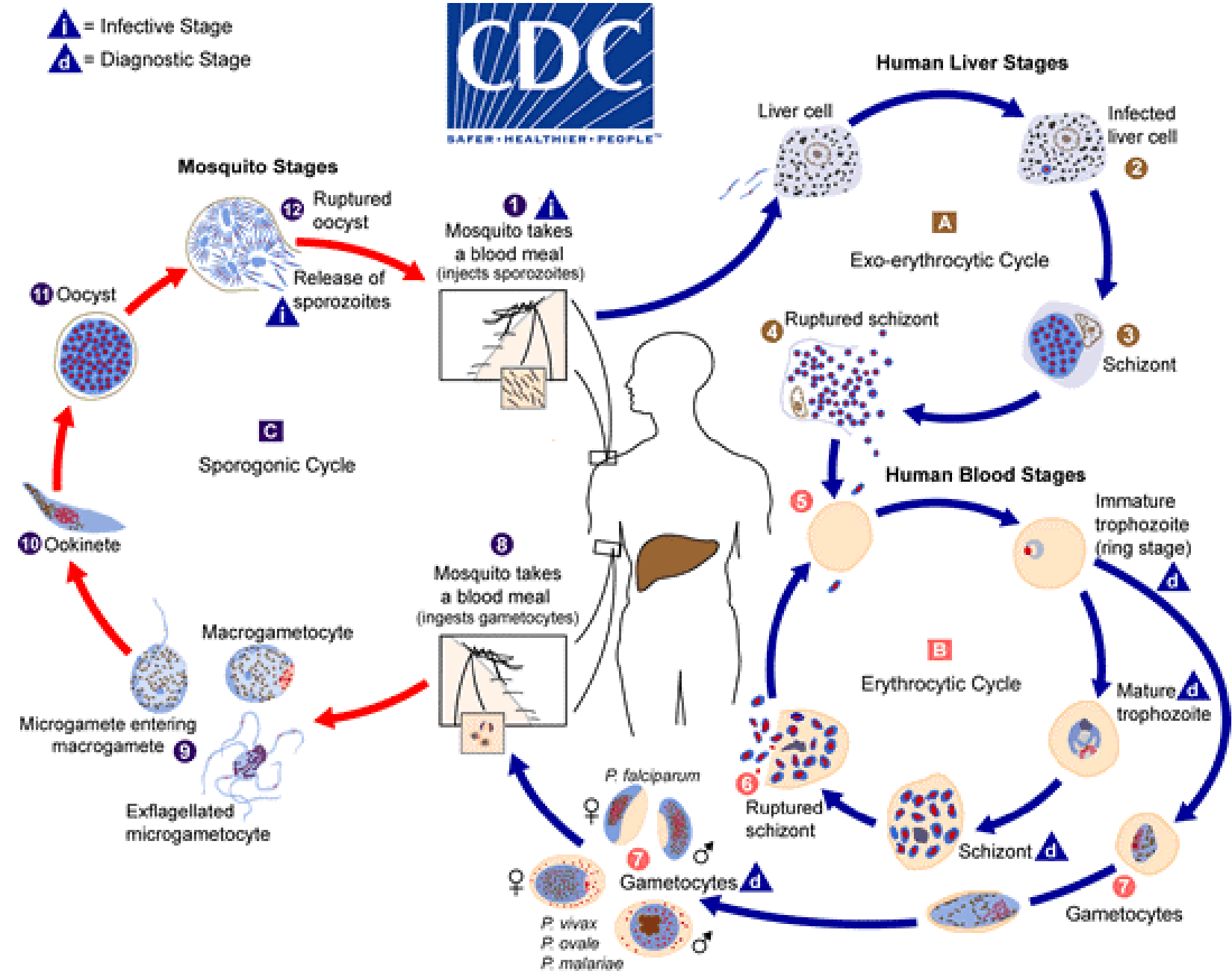

Figure 1 - Plasmodium falciparum life cycle (CDC 2017). 
Anopheles mosquito. As the mosquito performs blood repast, the salivary glands release sporozoites on the skin, and after reaching the bloodstream the sporozoites rapidly invade liver cells, starting the infection. In the liver cells, the sporozoites differentiate and multiply asexually into thousands of merozoites, which invade the erythrocytes and proceed to multiply. In this phase, begin the symptoms of malaria. Based on the species, the duration of the erythrocytic stage will be different: $48 \mathrm{~h}$ for $P$. falciparum, $P$. vivax and $P$. ovale and 72 h for $P$. malariae.

Some merozoites will not reproduce asexually; these develop into sexual forms called gametocytes, which are ingested by the female Anopheles mosquito during hematophagy, beginning the sexual cycle in the stomach of the mosquito. The new sporozoites move to the salivary glands of the mosquito, and their inoculation into a new human host restarts the life cycle of Plasmodium. Some merozoites evolve into a latent form of the parasite (hypnozoites), whose reactivation is responsible for the recurrence of malaria (in cases of infection caused by $P$. vivax and $P$. ovale) (Schlitzer 2008, Midha et al. 2015, MMV 2017a, CDC 2017).

\section{CURRENT CHEMOTHERAPY FOR MALARIA}

The main means used to eliminate or reduce the number of cases of malaria are the development of vaccines, vector control, chemoprophylaxis and chemotherapy employing antimalarial drugs (Rappuoli and Aderem 2011).

Antimalarials mostly act by mechanisms that seek to inhibit one or two stages of the parasite's life cycle. The treatment aims to act on the parasite in two different ways. One of them is to interrupt the schizogonic blood stage responsible for the symptoms of the disease, that is, to kill the parasite during the evolutionary cycle. The other is to employ drugs that prevent the development of gametocytes, in other words, to destroy the parasite in the tissue cycle of the species $P$. vivax and $P$. ovale, interrupting the transmission of the parasite and avoiding relapses. Various drugs are available for achieving these goals, where each acts in a specific way to inhibit the development of the parasite in the host (Teixeira et al. 2014, Biamonte et al. 2013).

Antimalarial chemotherapy has been based on an endless search for the next agent to combat Plasmodium parasites when they are able to prevent the effect of current drugs. A great challenge for malaria treatment in recent decades has been to overcome the parasite's ability to acquire resistance to antimalarials, requiring the development of more effective drugs (Seder et al. 2013, Raj et al. 2014, Teixeira et al. 2014).

Antimalarial chemotherapy is based on natural products, semi-synthetic and synthetic compounds developed since the 1940s. Safe drugs used in the treatment of the disease are divided into three main classes: quinoline derivatives (Figure 2), antifolates (Figure 3) and artemisinin derivatives (Figure 4) (Staines and Krishna 2012, Leite et al. 2013).

\section{QUINOLINE DERIVATIVES}

Historically, quinolines are among the most widely used drugs for the treatment of malaria. Quinine (QN 1) (Figure 2), an alkaloid isolated from the bark of Cinchona trees, was first used to treat malaria as early as the beginning of the 17th century, and became the standard therapy for malaria from the mid-19th century to the 1940s. The extraction of QN is still more economically viable than its synthetic production (Achan et al. 2011). The emergence of resistant strains of $P$. falciparum, in addition to the high toxicity, has contributed to the limitation of the use of QN. However, this drug still used against malaria in the clinic, most often combined with a second agent to shorten the duration of therapy and thus minimize the adverse effects (Achan et al. 2011, Giao and Vries 2001). 
<smiles>C=CC1CC2CN1CC2[C@H](O)c1ccnc2ccc(OC)cc12</smiles>

(1 QN)<smiles>COc1cc(NC(C)CCCN)c2ncccc2c1</smiles>

(5 PQ)<smiles>CCN(CC)CCCC(C)Nc1cc(OC)cc2cccnc12</smiles>

(2)<smiles>CCN(CC)CCCC(C)Nc1ccnc2cc(Cl)ccc12</smiles>

(3)

(4 CQ)<smiles>CCN(CC)Cc1cc(Nc2ccnc3cc(Cl)ccc23)ccc1O</smiles>

(6 AQ)<smiles>COc1ccc2nc3cc(Cl)ccc3c(Nc3cc(CN4CCCC4)c(O)c(CN4CCCC4)c3)c2n1</smiles>

(8 PYR)<smiles>Clc1ccc2c(N3CCN(CCCN4CCN(c5ccnc6cc(Cl)ccc56)CC4)CC3)ccnc2c1</smiles>

(7)<smiles>O[C@H](c1cc(C(F)(F)F)nc2c(C(F)(F)F)cccc12)[C@H]1CCCCN1</smiles>

(9 MQ)

Figure 2 - Quinoline derivatives used in the treatment of malaria.

At the beginning of the 20th century, research conducted by Bayer gave rise to the first synthetic antimalarial drug, an 8-aminoquinoline, pamaquine (2) (Figure 2), whose clinical use was abandoned due to its high toxicity and limited activity (Tekwani and Walker 2006). After this discovery came mepacrine, also known as quinacrine (3) (Figure 2), an acridine derivative that was widely used in the 1930s during World War II. During this time, Bayer discovered chloroquine (CQ 4) (Figure 2), a 4-aminoquinoline that has become the most important antimalarial drug due to its high efficacy, low cost, and tolerable adverse effects (Krafts et al. 2012, O’Neill et al. 2012, Teixeira et al. 2014). Being a weak base, CQ accumulates in the acidic food vacuole of the parasite and exerts its activity by binding free heme and inhibiting hematin biocrystallization (hemozoin formation). CQ was the first choice for antimalarial treatment for a long time, but its uncontrolled use soon led to the emergence of chloroquine-resistant (CQR) P. falciparum strains, only 15 years after the introduction of $\mathrm{CQ}$ as first-line antimalarial chemotherapy (Cunico et al. 2008, Kaur et al. 2010).

Primaquine (PQ 5) (Figure 2), an 8 -aminoquinoline clinically used since 1950 , is still the only drug used worldwide for the treatment of relapsing $P$. vivax malaria caused by hypnozoites, and it inhibits the formation of gametocytes (Waters and Edstein 2012).

This fact intensified the need to obtain new drugs with anti- $P$. vivax activity. New quinoline derivatives with side chain modifications were synthesized, giving rise to new drugs such as amodiaquine (AQ 6) (Figure 2), a 4-phenylaminoquinoline (Teixeira et al. 2014). 
Piperaquine (7) (Figure 2) is a bis-4aminoquinoline discovered in 1960s that showed activity against CQR strains. It is a bisquinoline, and although its precise mechanism of action is unknown, it is thought to be similar to that of CQ, which is structurally similar. The bulky bisquinoline structure of piperaquine (7) is postulated to inhibit transporter-mediated drug efflux, protecting the drug against CQR. However, high rates of resistance to 7 have been reported in areas where it has been widely used as a monotherapy (EMA 2017b, Keating 2012).

In the 1970s, pyronaridine (PYR 8) (Figure 2) was synthesized; a 10-phenyl aminobenzo[b][1,5] naphthyridine derivative that was active against drug-resistant $P$. falciparum strains (Kaur et al. 2010). After the emergence of parasite resistance to $\mathrm{CQ}$, AQ gained prominence, as this phenylsubstituted analogue of CQ was found to have an excellent activity/toxicity profile while possibly sharing its mechanism of antimalarial action with CQ (Teixeira 2014, Barnett and Guy 2014).

PYR was synthesized in 1970 in China and has been used there for over 30 years for the treatment of malaria. It has high potency against $P$. falciparum, including CQR strains. PYR inhibits the formation of b-hematin, thus preventing the malarial parasite from neutralizing heme, which is toxic to the parasite. Additionally, by forming a drug-hematin complex, PYR inhibits the glutathione-dependent degradation of hematin and enhances hematininduced lysis of red blood cells. Both these actions lead to parasite death. The activity of PYR against erythrocytic $P$. falciparum is greatest in the ring- form stage, followed by the schizonts, and then the trophozoites. It was more active against all of these stages than CQ (Croft et al. 2012).

Mefloquine (MQ 9) (Figure 2), developed by the United States Army, came into use in the mid-1980s and is currently recommended for chemoprophylaxis of malaria caused by all species. Mefloquine has been used in the fight against CQR strains; however, its use is associated with several side effects, and resistance to this drug has been reported. MQ is an antimalarial agent with high schizonticidal, but not gametocidal, activity. The exact mechanism of action of MQ is not clear. It does, however, have a high affinity for erythrocyte membranes, with activity presumably related to its interference with the polymerization of heme units (Nosten et al. 2012, Palmer 1993, WHO 2015).

\section{ANTIFOLATE DERIVATIVES}

Antifolates are an important class of antimalarials. However, many of these compounds are toxic to humans and have low oral tolerance. These drugs, besides acting as schizonticides in the blood in the treatment of malaria, can also be used to combat various other diseases, such as cancer. Antifolates are divided into two classes (I and II) according to their mechanisms of action. Sulfadoxines (10) (Figure 3) have structures similar to $p$-aminobenzoic acid (PABA) and belong to the type I class of antifolates. They block the production of dihydrofolic acid by inhibiting dihydropteroate synthase (DHPS), an essential enzyme for the synthesis of nucleic acids. Formerly, tests were conducted to use DHPS inhibitors alone as antimalarial agents, but this

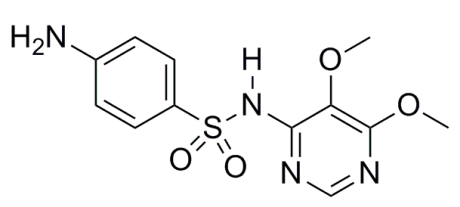

(10)

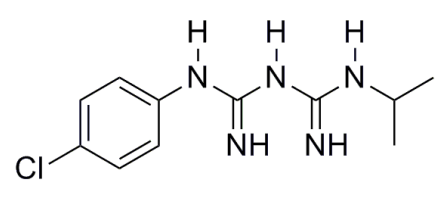

(11)<smiles>CCc1nc(N)nc(N)c1-c1ccc(Cl)cc1</smiles>

(12)

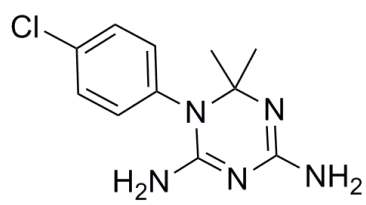

(13)

Figure 3 - Antifolates used in the treatment of malaria. 
method was abandoned due to problems of toxicity and low efficacy (Nzila 2012).

Proguanil (11) and pyrimethamine (12) (Figure 3) correspond to the type II class of antifolates and are powerful schizonticidal agents that act on asexual forms of the parasite. These drugs inhibit the dihydrofolate reductase (DHFR) in the parasite, suppressing the reduction of dihydrofolate to tetrahydrofolate, which is necessary for the synthesis of amino acids and nucleic acids (Nzila 2012).

Proguanil (11) is a prodrug that is metabolized to cycloguanil (13) (Figure 3); it was the first antifolate produced for the treatment of malaria. Its low toxicity is indispensable in prophylaxis because it acts by destroying parasites before they invade red blood cells during their passage into the bloodstream. Pyrimethamine (12) has been the most frequently employed antifolate administered in combination with other faster-acting drugs. Although it was initially developed as an anticancer drug, it was later recognized as an antimalarial because of its structural similarity to Proguanil (11). However, the use of this class has been decreased due to the development of resistance in parasites to these drugs (Nzila 2012, Barnett and Guy 2014).

\section{ARTEMISININ DERIVATIVES}

Artemisinin (ART 14) (Figure 4) was discovered by a Chinese scientist, Youyou Tu, who in 2015 shared the Nobel Prize for Medicine for her discovery, which lowered the mortality rates of people with malaria. In 1972, ART was isolated for the first time from a Chinese medicinal plant, Artemisia anпиа (an herbaceous plant of the family Asteraceae), and is a sesquiterpene lactone natural product. Since the discovery of the antimalarial activity of ART and its semi-synthetic derivatives, they have been used in the treatment of malaria as first-line drugs. In addition, ART is largely used in the treatment of some types of fever and is recommended in cases of severe malaria (Misra et al. 2014, França et al. 2008, The Nobel Foundation 2015).

In 1979, the use of ART was implemented in the rest of the world due to its unusual chemical structure and potent antimalarial activity. The semisynthesis of ART from artemisinic acid and a total synthesis in 1983 were results of a great interest in exploring strategies of chemical synthesis. ART has gained considerable attention as a chemotherapy against malaria, but activity against other parasites such as Schistosoma, Leishmania and Toxoplasma has also been described. In addition, it has been considered an imminent candidate to decrease coccidial infection in chickens. This drug and its semisynthetic derivatives have other biological effects, including antiviral and anticancer activities (Li and Zhou 2010, Karunajeewa 2012).

The chemical synthesis of ART is known to be expensive, and its main commercial sources are the field-grown leaves and flowering tops of $A$. апnиa. Therefore, the search for increased productivity follows two strands: the application of new strategies for genetic improvement and the

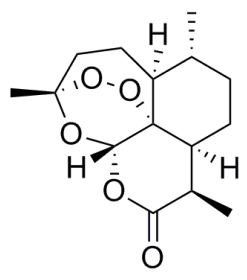

(14 ART)

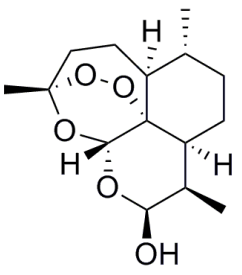

(15 DHA)

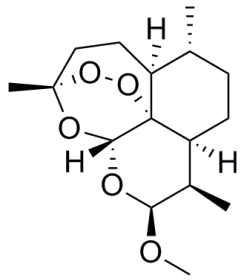

(16)

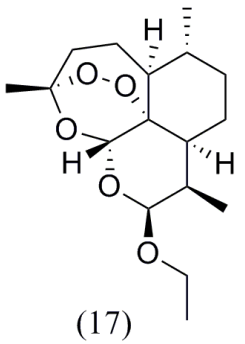

(17)

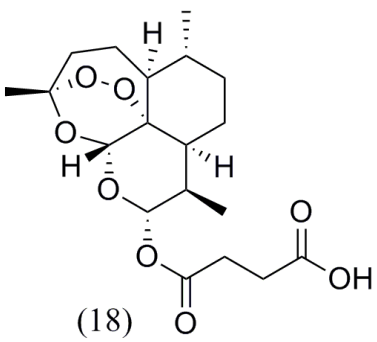

Figure 4 - Artemisinin derivatives used in the treatment of malaria. 
search for new Artemisia species (Misra et al. 2014, Wright et al. 2010).

ART and its derivatives, dihydroartemisinin (DHA 15), artemether (16) arteether (17) and artesunate (18) (Figure 4) are drugs that act by killing the parasites at an early phase of their development, quickly decreasing their numbers. Other characteristics of these drugs are low bioavailability and short half-life, which, in addition to previous reports of resistance, make them inefficient as monotherapies for the treatment of malaria. Therefore, these drugs are recommended in artemisinin-based combination therapy (ACT) (Araujo et al. 2009, WHO 2015).

Artemether (16) has several proposed mechanisms of action, including interfering with plasmodialtransport proteinsand with mitochondrial electron transport and producing free radicals to reduce blood antioxidants and glutathione. When used as a monotherapy, artemether has a relatively high recrudescence rate and is rapidly absorbed after oral dosing, reaching a maximum concentration in adults after approximately 2 hours. Once in systemic circulation, artemether (16) is hydrolyzed in the gut and liver to DHA. The bioavailability of 16 increases 2-fold when given in the presence of food (Karunajeewa 2012, WHO 2015).

Artesunate (18) is the most important semisynthetic derivative due to its rapid antimalarial action, lack of considerable clinical resistance and significantly greater solubility in water than ART, DHA or 16, which is favorable for the preparation of formulations (Haynes 2006, WHO 2015).

These drugs act on the gametocytes and are blood schizonticides, preventing the transmission to other hosts and reducing the propagation of resistant forms. Literature reports have shown that, in the presence of the ferrous ions from the heme group of hemoglobin, the endoperoxide bridge of these substances can undergo a reductive cleavage, generating free radicals that can alkylate or modify the proteins of the parasite, causing its death. O'Neill and co-workers described in detail the nature of the proposed radical and the mechanistic pathways bioactivation of artemisinin, the reductive scission model and the open peroxide model. (O’Neill et al. 2010, Na-Bangchang and Karbwang 2009).

ART is a sensitive molecule for large-scale derivatization. The carbonyl group can be easily reduced to a hydroxyl group, preserving the crucial endoperoxide moiety, using sodium borohydride to obtain DHA (15). This led to the preparation of a series of semisynthetic first-generation analogues: artemether (16); arteether (17); and artesunic acid, which is commercially known as artesunate (18) (Figure 4). These analogues share the same basic structure of ART with different substituents. The carbonyl exchange exerts influence on the solubility of each ART derivative and on some of their pharmacokinetic properties. ART itself is poorly soluble in water but is soluble in many aprotic organic solvents.

To increase antimalarial potency, researchers have become interested in synthesizing ART dimers, trimers and tetramers. Many of them have shown more promising antimalarial activity than ART and its first-generation analogs (Chaturvedi et al. 2010, Karunajeewa 2012).

ART derivatives, which are effective against chloroquine- and mefloquine-resistant strains, not only are active against the mature ring stage of $P$. falciparum, when the parasites are most metabolically active, but also target the young ring stages of the parasites. Another potential benefit is that they are active against the gametocytes transmitted from humans to mosquitoes and are capable of killing $>99.9 \%$ of parasites per asexual cycle. Their use results in a significant reduction in gametocytemia and subsequent decrease in the transmission to mosquitoes compared to the use of previous first-line non-artemisinin antimalarial drugs. However, these compounds are not active against the pre-erythrocytic stages or the dormant hypnozoite stages of $P$. vivax and $P$. ovale in the liver 
(Okell et al. 2008). Despite that, the concentration of ARTs needs to be at a parasiticidal level for at least 6 days (corresponding to three asexual life cycles for $P$. falciparum) to remove all parasites from the blood. Therefore, when administered alone, ARTs must be given as 7-day regimens to maximize their cure rates. However, compliance to 7-day treatment courses is poor, particularly when the clinical symptoms of malaria disappear within a couple of days of treatment initiation. When used in combination with partner drugs with longer elimination half-lives, 3-day treatment courses are sufficient (Nyunt and Plowe 2007).

\section{CURRENT COMBINATION CHEMOTHERAPY IN MALARIA}

The combination of a fast-acting ART derivative and a long-acting antimalarial with different mechanisms of action is called artemisinin-based combination therapy (ACT). The use of ACTs with at least two drugs is recommended by the WHO to prevent or reduce the development of antimalarial resistance. These combined therapies may act concomitantly through several mechanisms of action and in different biochemical targets of the parasite, achieving better results than monotherapy (WHO 2015).

Replacement of monotherapy by ACT has started in all countries where P. falciparum is endemic. ART derivatives are considered the basis for the treatment of $P$. falciparum malaria and are used to combat uncomplicated malaria. Several new pharmaceutical fixed-dose combination (FDC) formulations have been produced to treat this disease because of the high effectiveness and potency of ACT (WHO 2015).

Mixed malaria infections are frequent in endemic areas. These infections are characterized by contamination by more than one species of Plasmodium. People infected with serious $P$. vivax can also have $P$. falciparum infections, for example.
In addition, acute $P$. falciparum infections can be succeeded by a presumed relapse of $P$. vivax malaria. The treatment of choice for mixed malaria infections is ACTs because this therapy is efficient against all types of malaria (WHO 2015).

The ACTs for the treatment of malaria are as follows (Figures 5 - 11):

- Dihydroartemisinin (15) + piperaquine (7) (Eurartesim $^{\circledR} ; 19$ )

- Artemether (16) + lumefantrine (20) $\left(\right.$ Coartem $\left.^{\circledR} ; 21\right)$

- Artesunate (18) + mefloquine (9) (ASMQ; 22)

- Artesunate (18) + amodiaquine (6) (Winthrop $^{\circledR}$ or Coarsucam ${ }^{\mathrm{TM}}$; 23)

- Artesunate (18) + sulfadoxine (10) + pyrimethamine (7) (24)

- Pyronaridine (8) + artesunate (18) $\left(\right.$ Pyramax $\left.^{\circledR} ; 25\right)$, in development.

- $\mathrm{ARCO}^{\circledR}$ (combination 26 (artemisinin + naphthoquine (27))

Eurartesim $^{\circledR}$ (dihydroartemisinin + piperaquine - combination 19) (Figure 5) was developed by Sigma-Tau in partnership with the Medicines for Malaria Venture (MMV). In October 2011, the European Medicines Agency (EMA) granted marketing authorization for Eurartesim ${ }^{\circledR}$ for the treatment of uncomplicated $P$. falciparum malaria in adults. It is administered once a day for 3 days, making it easier for patients to comply with the dosing. In 2015, Sigma-Tau entered into an exclusive licensing agreement with Pierre Fabre

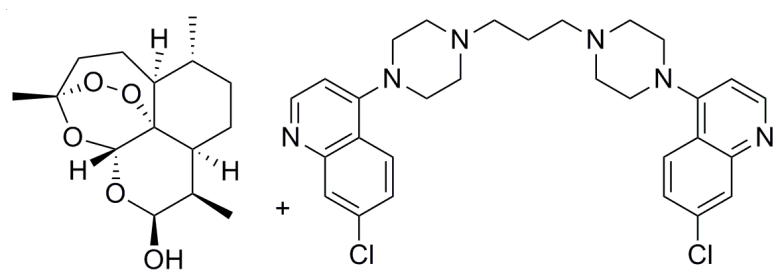

(Eurartesim $\mathbb{R} ; 19)$

Figure 5 - Structure of drugs used in Eurartesim ${ }^{\circledR}$ combination 19. 
to expand its ability to support country registration requirements and national adoption in 32 African countries. A pediatric formulation of Eurartesim ${ }^{\circledR}$ for children over $5 \mathrm{~kg}$ is in phase III clinical trials. In October 2015, Eurartesim ${ }^{\circledR}$ was prequalified by the WHO, and a dossier for a hydrodispersible childfriendly formulation of the drug was submitted to the EMA. Through this prequalification process, the WHO assesses and approves the quality, safety and efficacy of the medicinal product. DHA, the main active metabolite in Eurartesim ${ }^{\circledR}$, achieves high concentrations in red blood cells infected with P. falciparum (Valecha et al. 2010, Bassat et al. 2009, Nguyen et al. 2009, Schrader et al. 2012, Anthony et al. 2012, EMA 2017a, MMV 2017b).

Coartem ${ }^{\circledR}$ (artemether + lumefantrine (20) - combination 21) (Figure 6) is used in over 50 endemic countries to treat adults and children over $5 \mathrm{~kg}$ with uncomplicated $P$. falciparum infection, including mixed infection. Coartem ${ }^{\circledR}$ Dispersible, developed by Novartis and MMV, was approved in 2009 by Swissmedic and more recently by the EMA and the US Food and Drug Administration. It was the first prequalified child-friendly ACT as a sweet-tasting cherry-flavored tablet that disperses in a small amount of water. Moreover, antimalarial tablets for adults are bitter and need to be broken up or crushed, making it difficult to give the correct dosing (Anthony et al. 2012, Bassat et al. 2009, Sirima et al. 2016, MMV 2017c).

ASMQ (artesunate + mefloquine - combination 22) (Figure 7) is a formulation developed by a Brazilian government-owned pharmaceutical company, Farmanguinhos/Fiocruz, in partnership with the Drugs Initiative for Neglected Diseases (DNDi). ASMQ was transferred to the Indian pharmaceutical company Cipla and was prequalified by the WHO in 2012. The ASMQ combination therapy has been one of the WHOrecommended forms of ACT for first-line treatment of uncomplicated malaria in adults and children over $5 \mathrm{~kg}$ in several countries. The fixed dose containing
$100 \mathrm{mg}$ of artesunate and $220 \mathrm{mg}$ of mefloquine hydrochloride has demonstrated efficacy and safety. This combination is less commonly used in Africa because of the availability of other affordable and already registered ACTs (Anthony et al. 2012, Valecha et al. 2010, Wells et al. 2013).

Studies have shown that ASMQ had the highest cure rate, the lowest rate of gametocyte carriage, and the most effective suppression of $P$. vivax malaria. In addition, a large phase IV trial in Brazil confirmed its effectiveness for treating uncomplicated $P$. falciparum infection (Sirima et al. 2016, MMV 2017d).

Winthrop $^{\circledR}$ or Coarsucam ${ }^{\mathrm{TM}}$ (artesunate + amodiaquine - combination 23 (ASAQ)) (Figure 8) was developed by Sanofi and the DND $i$ and

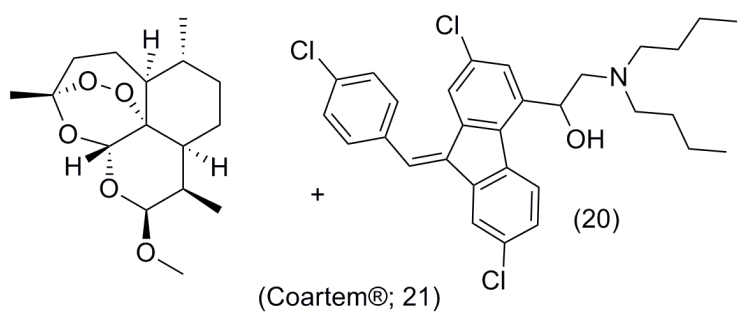

Figure 6 - Structure of drugs used in Coartem ${ }^{\circledR}$ combination 21.

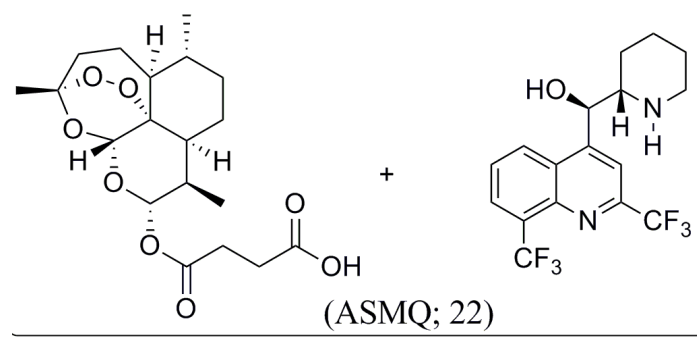

Figure 7 - Structure of drugs used in ASMQ combination 22.

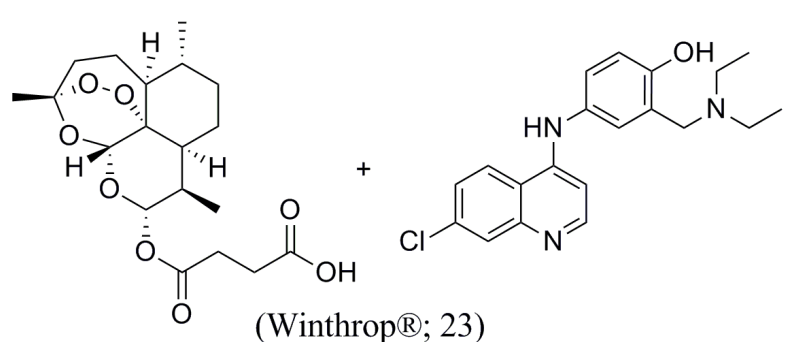

Figure 8 - Structure of drugs used in Winthrop ${ }^{\circledR}$ combination 23. 
was prequalified by the WHO in 2008. Winthrop ${ }^{\circledR}$ has been approved in 33 countries and has the lowest price of the fixed-dose ACTs. Winthrop ${ }^{\circledR}$ should be provided as a FDC to improve the severe adverse effects noted in the past associated with amodiaquine when administered as a monotherapy at high doses for treatment or prophylaxis.

As amodiaquine is effective against several CQR strains, this drug remains an important component of current antimalarial combination therapies, including being used with artesunate. The Winthrop ${ }^{\circledR}$ fixed-dose combination is effective in clearing $P$. falciparum parasites from infected individuals.

Winthrop $^{\circledR}$ is rapidly absorbed and undergoes rapid and extensive metabolism to DHA and desethylamodiaquine (Anthony et al. 2012, Navaratnam et al. 2009, Adjei et al. 2010, MMV 2017e).

The combination 24 (artesunate (18) + sulfadoxine (10) + pyrimethamine (12)) (Figure 9) is used for the treatment of acute uncomplicated malaria but is not available as a FDC yet. It is available in a blister pack containing $50 \mathrm{mg}$ of artesunate (18) and fixed-dose combination tablets comprising $500 \mathrm{mg}$ of sulfadoxine (10) and $25 \mathrm{mg}$ of pyrimethamine (12). A target dose of artesunate (18) is given once a day for 3 days, and a single administration of a single dose of sulfadoxine-pyrimethamine is given on the first day. This combination is the first-line therapy for uncomplicated $P$. falciparum malaria in Sudan and globally (WHO 2015, Matar et al. 2014).
Pyramax $^{\circledR}$ (pyronaridine + artesunatecombination 25) (Figure 10), co-developed by Shin Poong Pharmaceutical and MMV, is the first ACT for which the EMA has adopted a positive scientific opinion and is the first and only ACT to be approved for the blood-stage treatment of the main strains of malaria, namely, $P$. falciparum and $P$. vivax. It is also the first Korean product included in the WHO list of prequalified medicines for malaria. Pyramax $^{\circledR}$ is recommended for the treatment of uncomplicated malaria in adults and children over $20 \mathrm{~kg}$ (tablets) and in children between 5 and 20 $\mathrm{kg}$ (granules). Resistance to PYR appears slowly and is further retarded when used in combination with other antimalarials, particularly artesunate (Anthony et al. 2012, Schrader et al. 2012, MMV 2017f, Croft et al. 2012).

$\mathrm{ARCO}^{\circledR}$ (combination 26 (artemisinin + naphthoquine (27)) (Figure 11), recommended for the treatment of uncomplicated $P$. falciparum malaria, was developed in China to counter antimalarial drug resistance. Both artemisinin and naphthoquine drugs have proven to be efficacious, safe and well tolerated as monotherapies. $\mathrm{ARCO}^{\circledR}$ offers a novel advantage over existing ACTs: it can be administered as a single oral dose (or a 1-day treatment). Several therapeutic studies conducted recently indicate that a single oral dose administration of the artemisinin-naphthoquine combination is equally effective and safe as the 3-day treatment with the artemether-lumefantrine combination and other existing ACTs (Anthony et al. 2012, Biamonte et al. 2013).

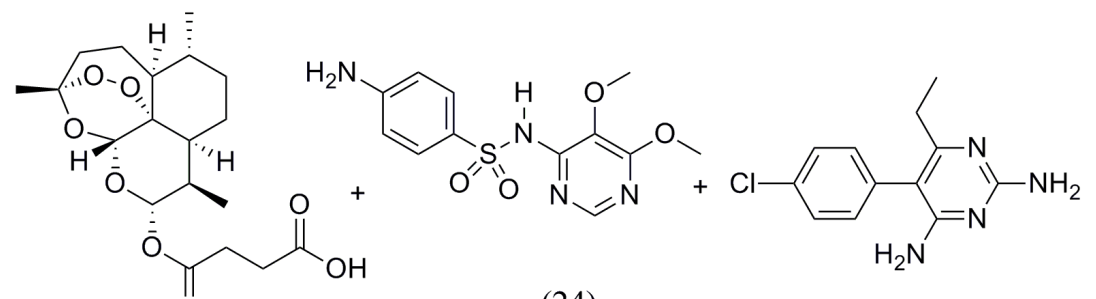

Figure 9 - Structure of drugs used in combination 24. 


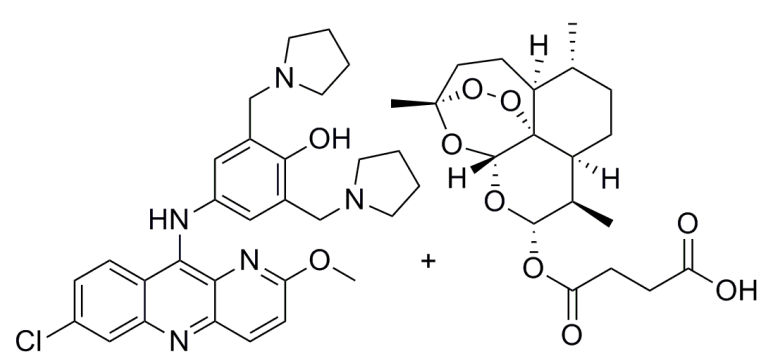

(Pyramax ${ }^{\circledR}$ 25)

Figure 10 - Structure of drugs used in Pyramax $^{\circledR}$ combination 25.
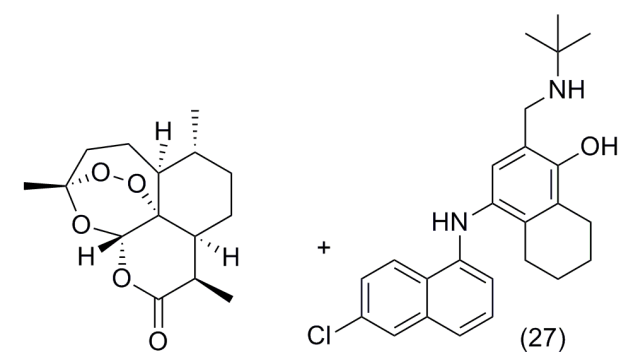

$\left(\operatorname{ARCO}^{\circledR} 26\right)$
Figure 11 - Structure of drugs used in $\mathrm{ARCO}^{\circledR}$ combination 26.

Other combinations without the presence of ART, such as sulfadoxine (10) + pyrimethamine (7) + amodiaquine (6), have been evaluated. This combination was more efficient than the substances that were employed singly but not as effective as ACTs (WHO 2015, MMV 2017g).

\section{ARTEMISININ HYBRIDS}

The combination of pharmacological fragments from two or more molecules into a single hybrid molecule as a strategy employed in medicinal chemistry for discovering new drugs is called molecular hybridization. There are several advantages of employing hybrid molecules instead of using multicomponent therapy. A hybrid is a single compound that can have double action; in other words, they can act by two distinct mechanisms or by a third, unique one, as these compounds are new pharmaceutical entities. A hybrid has the potential to increase safety, enhance efficacy, improve cost-effectiveness and reduce resistance to the original drugs. Another advantage would be a lower risk of drug interactions compared to a FDC (Vandekerckhove and D'hooghe 2015, Morphy and Rankovic 2005, Meunier 2008, Muregi and Ishih 2010).

ART-derivative hybrids that are active against Plasmodium strains are shown in Figures 12 and 13. Compound $\mathbf{2 8}$ is a conjugate hybrid between DHA (15) and QN (1) (Figure 12). The original vinyl functionality in QN was used to connect the molecules. The connection was obtained by coupling DHA to a carboxylic acid derivative of QN via a covalent ester linkage. Studies have shown that changes to other potential sites in QN had unfavorable effects on activity, supporting the change made in its vinyl functionality. The hydroxyl group and the quinoline ring are essential for activity, but the quinuclidine ring can be replaced by another one without loss of activity. The hybrid 28 was active in vitro against both sensitive $\left(3 \mathrm{D} 7 ; \mathrm{IC}_{50}=0.008 \mu \mathrm{M}\right)$ and resistant $\left(\mathrm{FcB} 1 ; \mathrm{IC}_{50}\right.$ $=0.009 \mu \mathrm{M})$ strains of $P$. falciparum. This shows that the hybrid has higher potency than ART (3D7, $\mathrm{FcB} 1 ; \mathrm{IC}_{50}=0.049$ and $0.050 \mu \mathrm{M}$, respectively) and QN (3D7, FcB1; $\mathrm{IC}_{50}=0.149$ and $0.096 \mu \mathrm{M}$, respectively) used as a control (Walsh et al. 2007, Teixeira et al. 2014).

The relevance of ART-based antimalarials in current clinical strategies against CQR malaria led to the exploration of several endoperoxides and derived hybrid constructs as potential antimalarial leads. Araujo (2009) developed the artemisinin/ quinacrine hybrid (29) (Figure 12) by joining the quinacrine core with an ART derivative, that features a metabolically stable linkage. The hybrid 29 was evaluated against CQS (3D7; $\left.\mathrm{IC}_{50}=0.012-0.016 \mu \mathrm{M}\right)$ and $\mathrm{CQR}\left(\mathrm{K} 1 ; \mathrm{IC}_{50}=\right.$ $0.014-0.020 \mu \mathrm{M}) P$. falciparum strains and was found to display micromolar activities against both strains, thus exhibiting no cross-resistance 


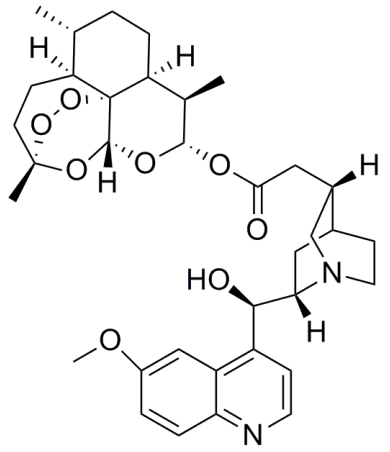

(28)

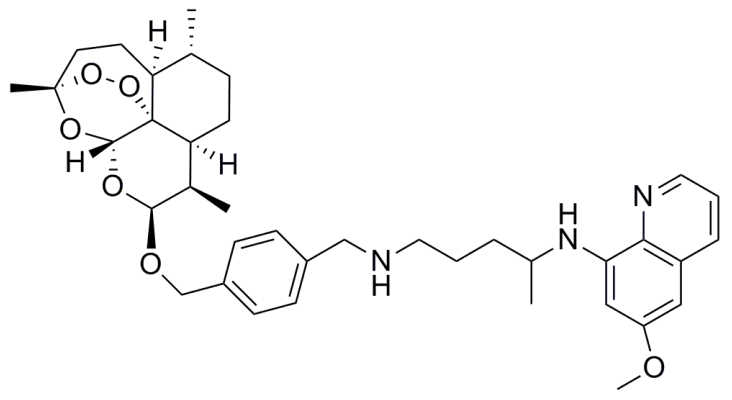

(30)

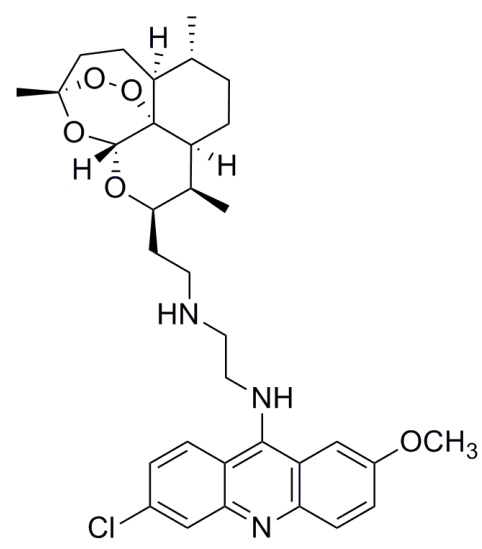

(29)<smiles>COc1cc(NC(C)CCCNC(=O)C[C@H]2O[C@@]34OO[C@@]5(CC[C@@H](C)[C@@H]3CC[C@@]5(C)OO4)[C@H]2C)c2ncccc2c1</smiles>

(31)

Figure 12 - Structures of ART hybrids 28-31.

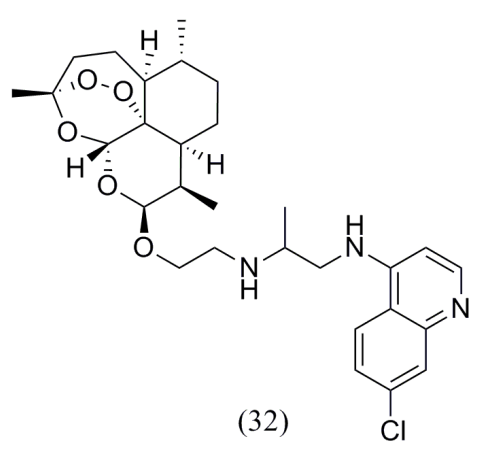

(32)

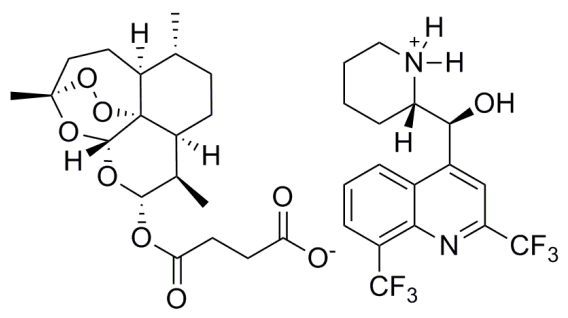

(34)

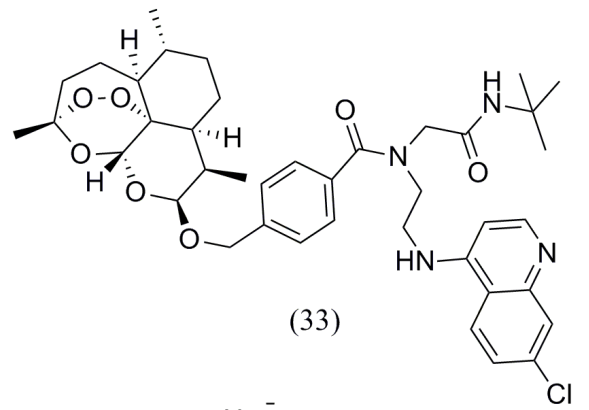<smiles>COc1cc(NC(C)CCC[NH3+])c2ncccc2c1</smiles>

(35)

Figure 13 - Structures of ART hybrids 32-35. 
with CQ. In fact, this hybrid was more active than ART (14) and was easily transformed into a water-soluble salt, making it suitable for oral and intravenous administration. Although this analogue is more potent than ART (3D7; $\left.\mathrm{IC}_{50}=0.011 \mu \mathrm{M}\right)$ $\left(\mathrm{K} 1 ; \mathrm{IC}_{50}=0.009 \mu \mathrm{M}\right)$, it was not more potent than artemether (16) $\left(3 \mathrm{D} 7 ; \mathrm{IC}_{50}=0.003 \mu \mathrm{M}\right)\left(\mathrm{K} 1 ; \mathrm{IC}_{50}\right.$ $=0.001 \mu \mathrm{M})$. This is surprising because it should accumulate within the acidic digestive vacuole much more efficiently than the parent drug, through an ion-trapping mechanism. This may indicate that other targets outside the food vacuole may be more important for this class of hybrid drug (Araujo et al. 2009, Kaur et al. 2010).

For DHA (15) / PQ (5) hybrids 30 and 31 (Figure 12), a double-drug approach was used by synthesizing molecular constructs where PQ (5) is covalently bound to the DHA core, another potent moiety with complementary antimalarial properties. Compound $\mathbf{3 0}$ was synthesized starting from artelinic acid, a 4-methylbenzoic acid derivative of ART (14) that has been shown to be the most metabolically stable of the ARTs. Compound $\mathbf{3 1}$ was designed by replacing the oxygen atom with a $\mathrm{CH}_{2}$ group. This modification was intended to produce a compound with greater hydrolytic stability, a longer half-life, and potentially lower toxicity. Both $\mathbf{3 0}$ and $\mathbf{3 1}$ displayed enhanced in vitro activities against liver-stage $P$. berghei compared to their parent drugs. They were also evaluated in vitro against $P$. falciparum $\mathrm{W} 2$ strains $\left(\mathrm{IC}_{50}=\right.$ 0.0125 and $0.0091 \mu \mathrm{M}$, respectively), in which they were equipotent to ART (14) and superior to PQ (5) (Capela et al. 2011).

Hybrid 32, a DHA (15) - 4-aminoquinoline hybrid (Figure 13), was developed by Lombard et al. (2011) by joining a DHA motif to 4-aminoquinoline via an ether/amine bond for the purpose of increasing the half-life of DHA. For solubility and stability reasons, this hybrid was treated with oxalic acid to obtain the oxalate salts.
Compound 32 exhibited higher potency against both CQS (D10; $\left.\mathrm{IC}_{50}=0.012 \mu \mathrm{M}\right)$ and CQR $\left(\mathrm{Dd} 2 ; \mathrm{IC}_{50}=0.017 \mu \mathrm{M}\right)$ strains than CQ (4). One drawback of the compound was its lower activity than DHA irrespective of the P. falciparum strain (Lombard et al. 2011, 2013).

Artemisinin/chloroquinoline hybrid 33 (Figure 13) was synthesized by Feng et al. (2011) by coupling DHA (15) and a chloroquinoline moiety through an ether/amide bond. The compound displayed excellent in vitro antiplasmodial activities against sensitive $\left(\mathrm{D} 10 ; \mathrm{IC}_{50}=0.027 \mu \mathrm{M}\right)$ and resistant $\left(\mathrm{K} 1 ; \mathrm{IC}_{50}=0.019 \mu \mathrm{M}\right) P$. falciparum strains compared to CQ (4). No cross-resistance with CQ was observed for this hybrid compound in CQR malaria parasites, even though it contains a CQ moiety. It was also found that this hybrid shares the same mechanism of action with both ART (14) and CQ, as it displayed potent activity against $\beta$-hematin formation and contributed to an increase in the accumulation of hemoglobin within the parasites (Feng et al. 2011, Vandekerckhove and D'Hooghe 2015).

MEFAS (34) (Figure 13) is a hybrid salt between artesunate (18) and MQ (9) that is under development by Boechat and co-workers (2014). MEFAS was active against $P$. falciparum CQS 3D7 and CQR W2, showing an $\mathrm{IC}_{50}$ value of $0.001 \mu \mathrm{M}$ for both strains. Studies have shown that MEFAS was at least 5-fold more potent than MQ alone, more potent than $\mathbf{1 8}$ against 3D7, as effective as 18 against $\mathrm{W} 2$, and more potent than mixtures of 18 with MQ. In in vivo tests in P. berghei infected mice, a cure was observed after treatment at a dose of $10 \mathrm{mg} / \mathrm{kg}$, without recrudescence of parasitemia. Assessments of the in vivo cytotoxicity of MEFAS showed that its toxicity is 5-fold lower than that of MQ and 3-fold lower than the FDC ASMQ.

Drugs that able to target both asexual parasites and gametocytes would improve malaria control. MEFAS has been shown to be an active blood schizonticidal drug. Its ability to block 


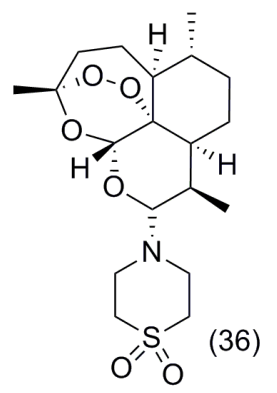

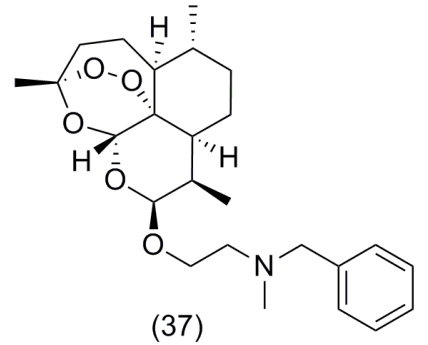

(37)

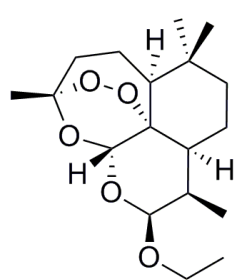

(38)

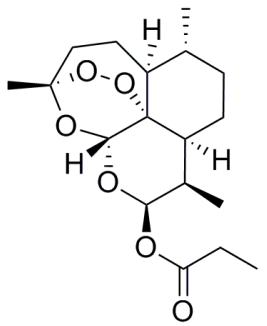

(39)

Figure 14 - Structures of ART derivatives 36-39.

the infectivity of $P$. falciparum gametocytes was evaluated, and it was found to be 280- and 15-fold more effective than MQ and $\mathbf{1 8}$ alone, respectively (Varotti et al. 2008, Penna-Coutinho et al. 2016)

PRIMAS (35) (Figure 13), which was designed using the same approach as MEFAS, is also a hybrid salt between artesunate (18) and PQ (5) under development by Boechat and co-workers (2014). PRIMAS was developed with the goal of minimizing the toxicity of PQ. The efficacy studies of the PRIMAS hybrid salt in in vivo and in vitro models showed that it is more active and less toxic than the isolated pattern drugs (Boechat et al. 2014).

Artemisone (36) (Figure 14) is a secondgeneration semi-synthetic ART (14) with the introduction ofapolarheterocycle. This modification improved pharmacokinetic properties and eliminated the neurotoxicity. It inhibits PfATPase6 with a $\mathrm{Ki}$ of $1.7 \mathrm{nM}$ and was approximately two to five times more efficient than artesunate (18) in animal experiments. Artemisone (36) had been in clinical studies, but further development was not reported (Anthony et al. 2012, Schrader et al. 2012, Barnett and Guy 2014).

A series of 10-aminoethylether derivatives of artemisinin were synthesized, and their antimalarial activity against $P$. falciparum was determined. The derivative 37 (Figure 14), containing only one nitrogen atom, showed the highest overall activity against a CQS strain (D10) $\left(\mathrm{IC}_{50}=1.44 \mathrm{nM}\right)$, while long-chain polyamine derivatives were found to have the lowest activity (Cloete et al. 2012).
The biotransformation of ART using $R$. stolonifer resulted in 10b-hydroxyartemisinin, a promising metabolite that was a precursor for the series of synthetic derivatives. Compound 10b-hydroxy-12b-arteether 38 (Figure 14) has significant anti-malarial activity $\left(\mathrm{IC}_{50}=18.29 \mathrm{nM}\right)$ compared to the natural drug ART (Gaur et al. 2014).

A series of esters were synthesized in a onestep reaction by derivatization on carbon $\mathrm{C}-10$ of DHA (15). The in vitro antiplasmodial activity was measured against $P$. falciparum 3D7 and K1 strains. The 10a-n-propyl ester (39) (Figure 14) exhibited the greatest activity against the 3D7 and K1 strains (0.0031 and $0.0003 \mathrm{mM}$, respectively), in comparison with artesunate (18) (Cloete et al. 2012).

A series of artesunate-polyamines were evaluated for antimalarial activity towards the K1 and NF54 strains of P. falciparum. (Bis)-Boc(bis)-artesunate-polyamine and (tetra)-artesunate polyamine conjugates exhibited potent in vitro activity towards both strains, with $\mathrm{IC}_{50}$ values in the range of 0.3-1.1 nM, comparable to the parent artesunate (18). The in vivo evaluation of compound 40 (Figure 14) demonstrated $99.8 \%$ reduction in parasitemia with maximal 30-day survival rates. Oral testing of $\mathbf{4 0}$ proved less efficacious, with $95.7 \%$ activity and inconsistent survival rates of 16-30 days (Pearce et al. 2017).

A series of artemisinin-vinyl sulfone hybrids was shown to display potent antiplasmodial 


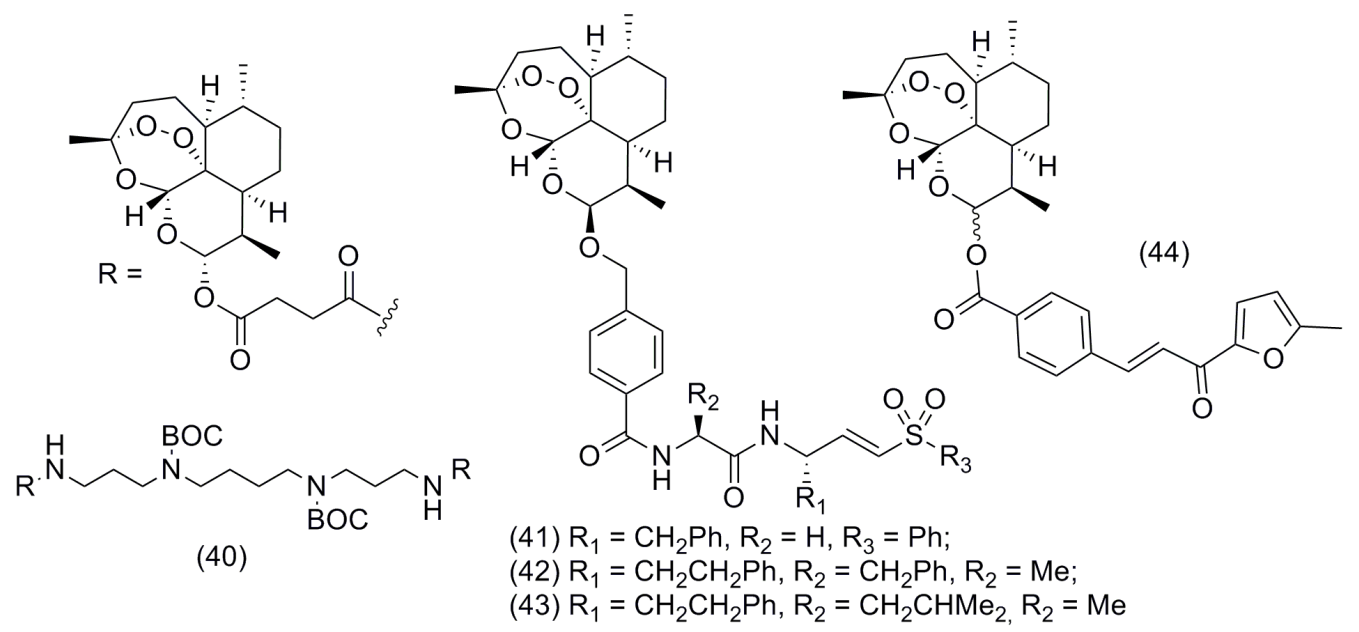

Figure 15 - Structures of ART derivatives 40-44.

activity against $P$. falciparum chloroquine-sensitive and multidrug-resistant strains W2 (chloroquineresistant), FCR3 (atovaquone-resistant), 3D7 (chloroquine-sensitive), V1/S (chloroquine- and pyrimethamine-resistant) and D6 (chloroquinesensitive and mefloquine-resistant). The $\mathrm{IC}_{50}$ values ranging from 0.002 to $0.005 \mathrm{mM}$ show the superior activity of compounds 41-43 (Figure 15) compared to CQ (4) and ART (14) against all strains (Capela et al. 2009, Muregi and Ishih 2010).

A series of dihydroartemisinyl-chalcone esters were screened against 3D7 and W2 strains of $P$. falciparum parasites. The esters featuring oxygenated aryl as ring $\mathrm{B}$ in the chalcone were found to be equipotent to DHA (15) but were two to three times more active than artesunate (18) and had more than fortyfold higher activity than CQ (4) against the W2 strain. Compound 44 (Figure 15) was identified as having the best activity, showing $\mathrm{IC}_{50}=0.0019 \mathrm{mM}$ and $0.0014 \mathrm{mM}$ against 3D7 and W2, respectively (Smit et al. 2015).

\section{DIMERIC ARTEMISININ DERIVATIVES}

It was thought that the extent of antimalarial activity depends upon the number of peroxide units, which can be increased by including an additional artemisinin moiety.
Thus, dimers, trimers and tetramers of artemisinin with various lengths, stereochemistries and flexibilities have been synthetized. ART trimer and tetramer derivatives without acetal groups have also been reported (Chaturvedi 2011).

Dimer 45 (Figure 16) had antimalarial activities in vitro against CQS P. falciparum parasites and was considerably more potent as an antimalarial $\left(\mathrm{IC}_{50}=0.00077 \mu \mathrm{M}\right)$ than ART (14) (Paik et al. 2006).

A series of ART (14) derivatives trioxane dimer esters were tested for antimalarial efficacy in malaria-infected mice at a single oral dose combined with MQ (9) $(6 \mathrm{mg} / \mathrm{kg}$ and $18 \mathrm{mg} /$ $\mathrm{kg}$, respectively). The most efficacious dimer 46 (Figure 16) prolonged mouse survival past day 30 of infection, with three of the four mice in this group having no detectable parasitemia and appearing and acting healthy on day 30 . The dimer esters outperformed the antimalarial drug artemether (16) (Conyers et al. 2015).

A series of ART (14) hybrids were synthesized and evaluated for their in vitro potential as antimalarial, antileukemia, and antiviral agents. Regarding the activity against $P$. falciparum 3D7 parasites. The dimer derivatives 47 and 48 (Figure 


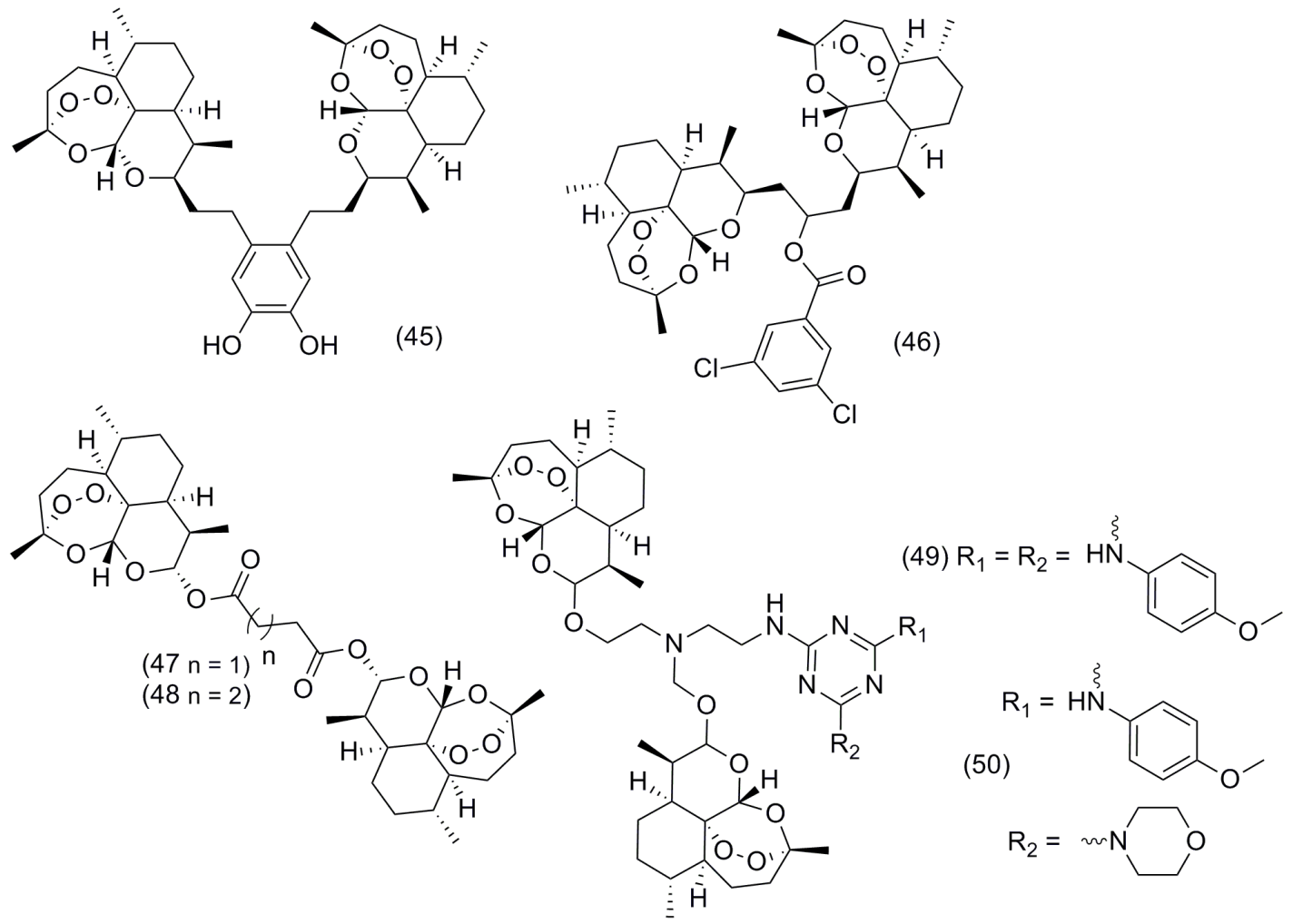

Figure 16 - Structures of ART dimer 45-50.

16) were more active $\left(\mathrm{IC}_{50}\right.$ value of $2.6 \mathrm{nM}$ for both) than the trimers (Reiter et al. 2015a).

A series of ART (14) and triazine hybrids were active against the CQS and CQR strains of $P$. falciparum. The dimer derivatives demonstrated higher activity than their monomeric counterparts. Compound 49 showed $\mathrm{IC}_{50}$ values of 0.0055 and $0.010 \mathrm{mM}$, and the compound $\mathbf{5 0}$ showed $\mathrm{IC}_{50}$ values of 0.0079 and $0.0102 \mathrm{mM}$ for NF54 and Dd2, respectively, possessing potencies comparable to those of artesunate (18) and DHA (15) against the NF54 strain while being slightly less active than both against the CQS strain (Figure 16) (Cloete et al. 2014).

Posner and co-workers described the administration of a single oral dose of only 5 $\mathrm{mg} / \mathrm{kg}$ of dimer secondary alcohol $51 \mathbf{a}$ or $\mathbf{5 1 b}$ plus $15 \mathrm{mg} / \mathrm{kg}$ of MQ (9) hydrochloride, which prolonged the lives of $P$. berghei-infected mice to an average of 25 days after infection. The result of this ACT combination is of high medicinal significance because the antimalarial efficacy of the drug artemether (16) plus MQ (9) under the same conditions was significantly lower. The carbamate derivatives 52-54 also significantly outperformed artemether (16) in prolonging the survival times (25-27 days) of malaria infected mice (Figure 17) (Conyers et al. 2014).

In another study, Posner and co-workers demonstrated that the partially curative carbonate and thiocarbonate derivatives all had average survival times (26-30 days) that were considerably higher than the average survival times of their parent dimer secondary alcohol 51a (19.5 days) (Mazzone et al. 2014).

The 1,2,4-trioxane-ferrocene hybrid $\mathbf{5 5}$ (Figure 17) was active against $P$. falciparum 3D7 strain, with a slightly higher $\mathrm{IC}_{50}$ value $(7.2 \mathrm{nM})$ than that of its parent compound DHA (15) (Reiter et al 2015b). 

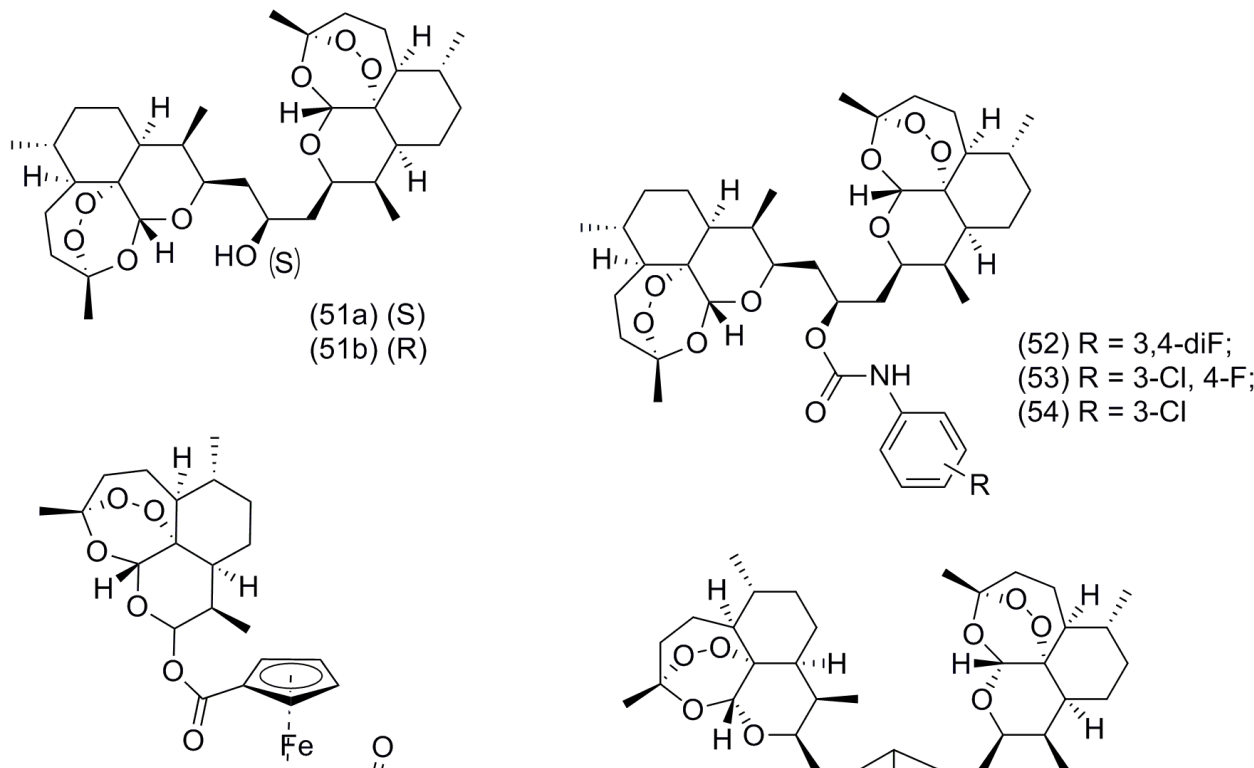

(55)
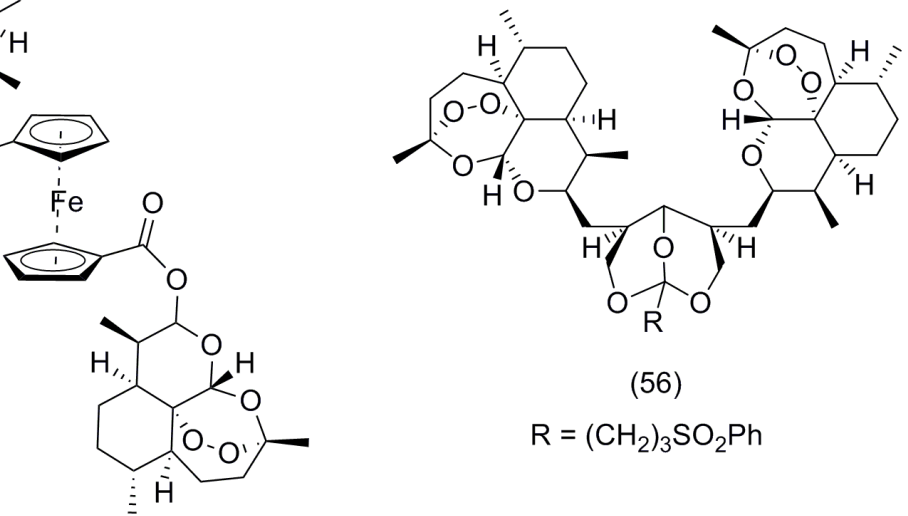

(56)

$\mathrm{R}=\left(\mathrm{CH}_{2}\right)_{3} \mathrm{SO}_{2} \mathrm{Ph}$

Figure 17 - Structures of ART dimer 51-56.
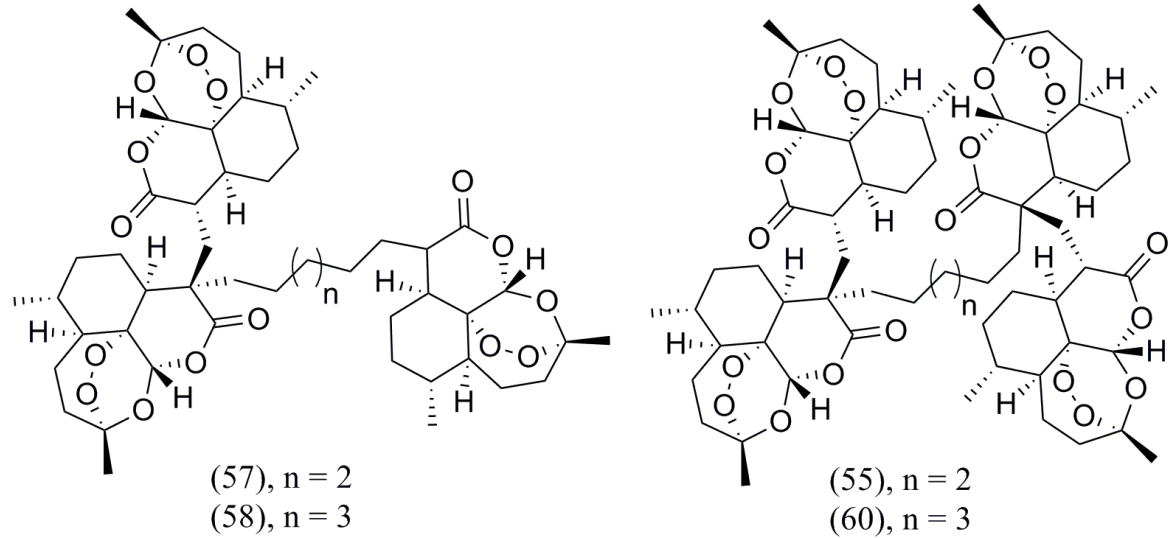

Figure 18 - Structures of ART trimer $\mathbf{5 7}$ and $\mathbf{5 8}$ and tetramer $\mathbf{5 9}$ and $\mathbf{6 0 .}$

The trioxane dimer orthoester sulfone 56 (Figure 17) was administered orally as a single oral dose $(6 \mathrm{mg} / \mathrm{kg})$ combined with mefloquine hydrochloride $(18 \mathrm{mg} / \mathrm{kg})$ in $P$. berghei-infected mice. The combination safely cured the mice after 30 days, and the efficacy was superior to that of artemether (16).

\section{TRIMERIC AND TETRAMERIC} ARTEMISININ DERIVATIVES

Trimers 57 and $\mathbf{5 8}$ and tetramers $\mathbf{5 9}$ and $\mathbf{6 0}$ (Figure 18) were synthesized and evaluated in relation to their antimalarial activities. The obtained results for trimers $57\left(\mathrm{EC}_{50}=0.0024 \mu \mathrm{M}\right)$ and $\mathbf{5 8}\left(\mathrm{EC}_{50}=\right.$ 
$0.0031 \mu \mathrm{M})$ and tetramers $59\left(\mathrm{EC}_{50}=0.0058 \mu \mathrm{M}\right)$ and $\mathbf{6 0}\left(\mathrm{EC}_{50}=0.02 \mu \mathrm{M}\right)$ were quite impressive and superior (except 60) to those for ART $\left(\mathrm{EC}_{50}=0.012\right.$ $\mu \mathrm{M})$ (Chaturvedi et al. 2010).

\section{CONCLUSIONS}

This review describes the drugs based on artemisinin and its derivatives that are recommended by the WHO for the treatment of malaria. Semisynthetic artemisinin derivatives, including dimers, trimers and tetramers, were developed as prototypes of the most important class of compound used in the fight against this disease. ACT is a combination of artemisinin derivatives that acts rapidly clears parasites from the blood while the partner drug acts more slowly cleaning the remaining parasites and provides protection against development of resistance to the artemisinin derivatives. New artemisinin derivatives can be the key to discover new drugs to be used in combination with other antimalarials or as monotherapies.

\section{ACKNOWLEDGMENTS}

The authors thank the Coordenação de Aperfeiçoamento de Pessoal de Nível Superior (CAPES) and the Conselho Nacional de Desenvolvimento Científico e Tecnológico (CNPq) for the fellowships granted to the authors. We also thank the Foundation for Research of the State of Rio de Janeiro (FAPERJ), Technological Development Program on Products for Health (PDTIS), for financial support. NB is the recipient of research productivity fellowships from the $\mathrm{CNPq}$ and from FAPERJ (“Cientista do Nosso Estado”).

\section{REFERENCES}

ACHAN J, TALISUNA AO, ERHART A, YEKA A, TIBENDERANA JK, BALIRAINE FN, ROSENTHAL PJ AND D'ALESSANDRO U. 2011. Quinine, an old antimalarial drug in a modern world: role in the treatment of malaria. Malar J 10: 144-156.
ADJEI GO, KUDZI W, DODOO A AND KURTZHALS JAL. 2010. Artesunate plus amodiaquine combination therapy: reviewing the evidence. Drug Dev Res 71: 33-43.

ANTHONY MP, BURROWS JN, DUPARC S, MOEHRLE JJ AND WELLS TN. 2012. The global pipeline of new medicines for the control and elimination of malaria. Malaria J 11: 316.

ARAUJO NCP, BARTON V, JONES M, STOCKS PA, WARD SA, DAVIES J, BRAY PG, SHONE AE, CRISTIANO MLS AND O'NEILL PM. 2009. Semi-synthetic and synthetic 1,2,4-trioxaquines and 1,2,4-trioxolaquines: synthesis, preliminary SAR and comparison with acridine endoperoxide conjugates. Bioorg Med Chem Lett 19: 2038-2043.

BARNETT DS AND GUY RK. 2014. Antimalarials in Development in 2014. Chem Rev 114: 11221-11241.

BASSAT Q ET AL. 2009. Dihydroartemisinin-piperaquine and artemether-lumefantrine for treating uncomplicated malaria in African children: a randomised, non-inferiority trial. PLoS ONE 4: e7871.

BIAMONTE MA, WANNER J AND LE ROCH KG. 2013. Recent advances in malaria drug discovery. Bioorg Med Chem Lett 23: 2829-2843.

BOECHAT N, SOUZA MVN, VALVERDE AL AND KRETTLI AU. 2014. Compounds derived from artesunate, preparation process, pharmaceutical composition and use of the respective medicine. US Patent 8802701B2.

CAPELA R, OLIVEIRA R, GONÇALVES LM, DOMINGOS A, GUT J, ROSENTHAL PJ, LOPES F AND MOREIRA R. 2009. Artemisinin-dipeptidyl vinyl sulfone hybrid molecules: Design, synthesis and preliminary SAR for antiplasmodial activity and falcipain-2 inhibition. Bioorg Med Chem Lett 19: 3229-3232.

CAPELA R, CABAL GG, ROSENTHAL PJ, GUT J, MOTA MM, MOREIRA R, LOPES F AND PRUDÊNCIO M. 2011. Design and evaluation of primaquine-artemisinin hybrids as a multistage antimalarial strategy. Antimicrob Agents Chemother 55: 4698-4706.

CDC - CENTERS FOR DISEASE CONTROL AND PREVENTION. 2017. Disponível em: http://www.cdc. gov/malaria/about/biology/index.html. Accessed: 16 November 2017.

CHATURVEDI D. 2011. Sesquiterpene lactones: structural diversity and their biological activities. In: Tiwari VK AND Mishra BB (Eds), Opportunity, Challenge and Scope of Natural Products in Medicinal Chemistry. Kerala. India: Research Signpost, p. 313-334.

CHATURVEDI D, GOSWAMI A, SAIKIA PP, BARUA NC AND RAO PG. 2010. Artemisinin and its derivatives: a novel class of anti-malarial and anti-cancer agents. Chem Soc Rev 39: 435-454.

CLOETE TT, BREYTENBACH JW, KOCK C, SMITH PJ, JBREYTENBACH JC AND N'DA DD. 2012. Synthesis, 
antimalarial activity and cytotoxicity of 10-aminoethylether derivatives of artemisinin. Bioorg Med Chem 20: 47014709.

CLOETE TT, KOCK C, SMITH PJ AND N'DA DD. 2014. Synthesis, in vitro antiplasmodial activity and cytotoxicity of a series of artemisininetriazine hybrids and hybriddimers. Eur J Med Chem 76: 470-481.

CONYERS RC, MAZZONE JR, SIEGLER MA, TRIPATHI AK, SULLIVAN DJ, MOTT BT AND POSNER GH. 2014. The survival times of malaria-infected mice are prolonged more by several new two-carbon-linked artemisinin-derived dimer carbamates than by the trioxane antimalarial drug artemether. Bioorg Med Chem Lett 24: 1285-1289.

CONYERS RC, MAZZONE JR, TRIPATHI AK, SULLIVAN DJ AND POSNER GH. 2015. Antimalarial chemotherapy: Orally curative artemisinin-derived trioxane dimer esters. Bioorg Med Chem Lett 25: 245-248.

CROFT SL, DUPARC S, ARBE-BARNES SJ, CRAFT JC, SHIN CS, FLECKENSTEIN L, BORGHINI-FUHRER I AND RIM HJ. 2012. Review of pyronaridine anti-malarial properties and product characteristics. Malar J 11: 270298.

CUNICO W, CARVALHO SA, GOMES CRB AND MARQUES GH. 2008. Fármacos antimalariais - história e perspectivas. Rev Bras Farm 89: 49-55.

EMA - EUROPEAN MEDICINE AGENCY. 2017a. Science Medicine Health. http://www.ema.europa.eu/docs/ en_GB/document_library/Medicine_for_use_outside EU/2012/06/WC500129288.pdf. Accessed: 08 September 2017.

EMA - EUROPEAN MEDICINE AGENCY. 2017b. Science Medicine Health. Eurartesim (dihydroartemisinin/ piperaquine) $20 \mathrm{mg} / 160 \mathrm{mg}$ and $40 \mathrm{mg} / 320 \mathrm{mg}$ filmcoated tablets: EU summary of product characteristics. http://www.ema.europa.eu/docs/en_GB/document library/EPAR__Product_Information/human/001199/ WC500118113.pdf. Accessed: 08 September 2017.

FENG TS, GUANTAI EM, NELL M, VAN RENSBURG CEJ, NCOKAZI K, EGAN TJ, HOPPE HC AND CHIBALE K. 2011. Effects of highly active novel artemisininchloroquinoline hybrid compounds on b-hematin formation, parasite morphology and endocytosis in Plasmodium falciparum. Biochem Pharmacol 82: 236247.

FRANÇA TCC, SANTOS MG AND FIGUEROA-VILLAR JD. 2008. Malária: aspectos históricos e quimioterapia. Quim Nova 31: 1271-1278.

GARCIA LS. 2010. Malaria. Clin Lab Med 30: 93-129.

GAUR R, DAROKAR MP, AJAYAKUMAR PV, SHUKLA RS AND BHAKUNI RS. 2014. In vitro antimalarial studies of novel artemisinin biotransformed products and its derivatives. Phytochemistry 107: 135-140.
GIAO PT AND VRIES PJ. 2001. Pharmacokinetic interactions of antimalarial agents. Clin Pharmacokinet 40: 343-373.

HAYNES RK. 2006. From artemisinin to new artemisinin antimalarials: biosynthesis, extraction, old and new derivatives, stereochemistry and medicinal chemistry requirements. Curr Top Med Chem 6: 509-537.

KAUR K, JAIN M, REDDY RP AND JAIN R. 2010. Quinolines and structurally related heterocycles as antimalarials. Eur J Med Chem 45: 3245-3264.

KARUNAJEEWA HA. 2012. Artemisinins: Artemisinin, Dihydroartemisinin, Artemether and Artesunate. In: Staines HM and Krishna S (Eds), Treatment and Prevention of Malaria. Antimalarial Drug Chemistry, Action and Use. London, United Kingdom. Springer Basel AG, p. 157-190.

KEATING GM. 2012. Dihydroartemisinin/Piperaquine: a review of its use in the treatment of uncomplicated Plasmodium falciparum malaria. Drugs 72: 937-961.

KRAFTS K, HEMPELMANN E AND SKÓRSKA-STANIA A. 2012. From methylene blue to chloroquine: a brief review of the development of an antimalarial therapy. Parasitol Res 111: 1-6.

LEITE FHA, FONSECA A, NUNES RR, JÚNIOR MC, VAROTTI FP AND TARANTO AG. 2013. Malaria: from old drugs to new molecular targets. Biochem Biotechnol Rep 2: 59-76.

LI J AND ZHOU B. 2010. Biological Actions of Artemisinin: Insights from Medicinal Chemistry Studies. Molecules 15: 1378-1397.

LOMBARD MC, N'DA DD, VAN BA CT, WEIN S, NORMAN J, WIESNER L AND VIAL H. 2013. Potent in vivo anti-malarial activity and representative snapshot pharmacokinetic evaluation of artemisinin-quinoline hybrids. Malar J 12: 71.

LOMBARD MC, N'DA DD, BREYTENBACH JC, SMITH PJ AND LATEGAN CA. 2011. Synthesis, in vitro antimalarial and cytotoxicity of artemisininaminoquinoline hybrids. Bioorg Med Chem Lett 21: 1683-1686.

MATAR KM, AWAD AI AND ELAMIN SB 2014. Pharmacokinetics of artesunate alone and in combination with sulfadoxine/pyrimethamine in healthy Sudanese volunteers. Am J Trop Med Hyg 90: 1087-1093.

MAZZONE JR, CONYERS RC, TRIPATHI AK, SULLIVAN DJ AND POSNER GH. 2014. Antimalarial chemotherapy: Artemisinin-derived dimer carbonates and thiocarbonates. Bioorg Med Chem Lett 24: 2440-2443.

MEUNIER B. 2008. Hybrid Molecules with a Dual Mode of Action: Dream or Reality? Accounts Chem Res 41: 69-77.

MIDHA K, MOHIT, NAGPAL M AND SHARMA A. 2015. Drug-resistant malaria in South Asian countries: a review of evidence and future prospects of nanomedicine based strategies for prophylaxis and treatment. EJPMR 2: 231248. 
MISRA H, MEHTA D, MEHTA BK AND JAIN DC. 2014. Extraction of Artemisinin, an Active Antimalarial Phytopharmaceutical from Dried Leaves of Artemisia annua L., Using Microwaves and a Validated HPTLCVisible Method for Its Quantitative Determination. Chromatogr Res Int: Article ID 361405.

MMV - MEDICINES FOR MALARIA VENTURE. 2017a. Parasite Lifecycle. https://www.mmv.org/malariamedicines/parasite-lifecycle Accessed: 21 September 2017.

MMV - MEDICINES FOR MALARIA VENTURE. 2017b. http://www.mmv.org/access/products-projects/eurartesimdihydroartemisinin-piperaquine Accessed: 21 September 2017.

MMV - MEDICINES FOR MALARIA VENTURE. 2017c. http://www.mmv.org/access/products-projects/coartemdispersible-artemether-lumefantrine/coartem-dispersiblefacts Accessed: 21 September 2017.

MMV - MEDICINES FOR MALARIA VENTURE. 2017d. https://www.mmv.org/access/products-projects/asmqartesunate-mefloquine Accessed: 21 September 2017

MMV - MEDICINES FOR MALARIA VENTURE. 2017e. https://www.mmv.org/access/products-projects/asaqwinthrop-artesunate-amodiaquine Accessed: 21 September 2017

MMV - MEDICINES FOR MALARIA VENTURE. $2017 \mathrm{f}$. http://www.mmv.org/access/products-projects/pyramaxpyronaridine-artesunate. Accessed: 21 September 2017.

MMV - MEDICINES FOR MALARIA VENTURE. 2017g. https://www.mmv.org/access/products-projects/spaqsulfadoxine-pyrimethamine-amodiaquine Accessed: 21 September 2017.

MORPHY R AND RANKOVIC Z. 2005. Designed Multiple Ligands. An Emerging Drug Discovery Paradigm. J Med Chem 48: 6523-6543.

MUREGI FW AND ISHIH A. 2010. Next-generation antimalarial drugs: hybrid molecules as a new strategy in drug design. Drug Dev Res 71: 20-32.

NA-BANGCHANG K AND KARBWANG J. 2009. Current status of malaria chemotherapy and the role of pharmacology in antimalarial drug research and development. Fundam Clin Pharmacol 23: 387-409.

NAVARATNAM V, RAMANATHAN S, WAHAB MSA, HUA SG, MANSOR SM, KIECHEL JR, VAILLANT M, TAYLOR WRJ AND OLLIARO P. 2009. Tolerability and pharmacokinetics of non-fixed and fixed combinations of artesunate and amodiaquine in Malaysian healthy normal volunteers. Eur J Clin Pharmacol 65: 809-821.

NGUYEN DVH, NGUYEN QP, NGUYEN ND, NGUYEN TD, DINH DN, NGUYEN TX, BUI D, CHAVCHICH M AND EDSTEIN MD. 2009. Pharmacokinetics and ex vivo pharmacodynamics antimalarial activity of dihydroartemisinin-piperaquine in patients with uncomplicated falciparum malaria in Vietnam. Antimicrob Agents Chemother 53: 3534-3537.

NOSTEN F, PHILLIPS-HOWARD PA AND TER KUILE FO. 2012. Other 4-Methanolquinolines, Amyl Alcohols and Phentathrenes: Mefloquine, Lumefantrine and Halofantrine. In: Staines HM and Krishna S (Eds), Treatment and Prevention of Malaria. Antimalarial Drug Chemistry, Action and Use. London, United Kingdom. Springer Basel AG, p. 95-112.

NYUNT MM AND PLOWE CV. 2007. Pharmacologic advances in the global control and treatment of malaria: Combination therapy and resistance. Clin Pharmacol Ther 82: 601-605.

NZILA A. 2012. Antifolates: Pyrimethamine, Proguanil, Sulphadoxine and Dapsone. In: Staines HM and Krishna S (Eds), Treatment and Prevention of Malaria. Antimalarial Drug Chemistry, Action and Use. London, United Kingdom. Springer Basel AG, p. 113-126.

O'NEILL PM, BARTON VE AND WARD SA. 2010. The Molecular Mechanism of Action of Artemisinin-The Debate Continues. Molecules 15: 1705-1721.

O'NEILL PM, BARTON VE, WARD SA AND CHADWICK J. 2012. 4-Aminoquinolines: Chloroquine, Amodiaquine and Next-Generation Analogues. In: Staines HM and Krishna S (Eds), Treatment and Prevention of Malaria. Antimalarial Drug Chemistry, Action and Use. London, United Kingdom. Springer Basel AG, p. 19-44.

OKELL LC, DRAKELEY CJ, GHANI AC, BOUSEMA T AND SUTHERLAND CJ. 2008. Reduction of transmission from malaria patients by artemisinin combination therapies: A pooled analysis of six randomized trials. Malar J 7: 125-138.

PAIK IH, XIE S, SHAPIRO TA, LABONTE T, SARJEANT AAN, BAEGE AC AND POSNER GH. 2006. Second generation, orally active, antimalarial, artemisinin-derived trioxane dimers with high stability, efficacy, and anticancer activity. J Med Chem 49: 2731-2734.

PALMER KJ, HOLLIDAY SM AND BROGDEN RN. 1993. Mefloquine. A review of its antimalarial activity, pharmacokinetic properties and therapeutic efficacy. Drugs 45: 430-475.

PEARCE AN, KAISER M AND COPP BR. 2017. Synthesis and antimalarial evaluation of artesunate-polyamine and trioxolanepolyamine conjugates. Eur J Med Chem 40: 595-603.

PENNA-COUTINHO J, ALMELA MJ, MIGUEL-BLANCO C, HERREROS E, SÁ PM, BOECHAT N AND KRETTLI AU. 2016. Transmission-Blocking Potential of MEFAS, a Hybrid Compound Derived from Artesunate and Mefloquine. Antimicrob Agents Chemother 60: 31453147. 
RAJ DK ET AL. Antibodies to PfSWA-1 block parasite egress from RBCs and protect against malaria infection. Science 344: 871-877.

RAPPUOLI R AND ADEREM A. 2011. A 2020 vision for vaccines against HIV, tuberculosis and malaria. Nature 473: 463-469.

REITER C, FROHLICH, L. GRUBER L, HUTTERER C, MARSCHALL M, VOIGTLÄNDER C, FRIEDRICH O, KAPPES B, EFFERTH T AND TSOGOEVA SB. 2015a. Highly potent artemisinin-derived dimers and trimers: Synthesis and evaluation of their antimalarial, antileukemia and antiviral activities Bioorg Med Chem 23: 5452-5458.

REITER C, FROHLICH T, ZEINO M, MARSCHALL M, BAHSI H, LEIDENBERGER M, FRIEDRICH O, KAPPES B, HAMPEL F, EFFERTH T, TSOGOEVA SB. 2015b. New efficient artemisinin derived agents against human leukemia cells, human cytomegalovirus and Plasmodium falciparum: 2nd generation 1,2,4-trioxaneferrocene hybrids. Eur J Med Chem 97: 164-172.

SCHLITZER M. 2008. Antimalarial Drugs - What is in Use and What is in the Pipeline. Arch Pharm Chem Life Sci 341: 149-163.

SCHRADER FC, MARLENE BARHO M, STEINER I, ORTMANN R AND SCHLITZER M. 2012. The antimalarial pipeline - An update. Int J Med Microbiol 302: 165-171.

SEDER RA ET AL. 2013. Protection against malaria by intravenous immunization with a nonreplicating sporozoite vaccine. Science 341: 1359-1365.

SIRIMA SB ET AL. 2016. Comparison of artesunatemefloquine and artemether-lumefantrine fixed-dose combinations for treatment of uncomplicated Plasmodium falciparum malaria in children younger than 5 years in subSaharan Africa: a randomised, multicentre, phase 4 trial. Lancet Infect Dis 16: 1123-1133.

SMIT FJ, VAN BILJON RA, BIRKHOLTZ L-M AND N'DA DD. 2015. Synthesis and in vitro biological evaluation of dihydroartemisinyl-chalcone esters. Eur J Med Chem 90: 33-44.

STAINES HM AND KRISHNA S. 2012. Treatment and Prevention of Malaria. Antimalarial Drug Chemistry, Action and Use. London, United Kingdom. Springer Basel AG, p. 19-44.

TEIXEIRA C, VALE N, PÉREZ B, GOMES A, GOMES JRB AND GOMES P. 2014. "Recycling" Classical Drugs for Malaria. Chem Rev 114: 1164-11220.
TEKWANI BLAND WALKER LA. 2006. 8-Aminoquinolines: future role as antiprotozoal drugs. Curr Opin Infect Dis 19: 623-631.

THE NOBEL FOUNDATION. 2015. The Nobel Prize in Physiology or Medicine 2015. http://www.nobelprize.org/ nobel_prizes/medicine/laureates/2015/press.pdf Accessed: 10 September 2017.

VALECHA N ET AL. 2010. An open-label, randomised study of dihydroartemisinin-piperaquine versus artesunatemefloquine for falciparum malaria in Asia. PLoS One 5: e11880.

VANDEKERCKHOVE S AND D'HOOGHE M. 2015. Quinoline-based antimalarial hybrid compounds. Bioorg Med Chem 23: 5098-5119.

VAROTTI FP ET AL. 2008. Synthesis, antimalarial activity, and intracellular targets of MEFAS, a new hybrid compound derived from mefloquine and artesunate. Antimicrob Agents Chemother 52: 3868-3874.

WALSH JJ, COUGHLAN D, HENEGHAN N, GAYNOR C AND BELL A. 2007. A novel artemisinin-quinine hybrid with potent antimalarial activity. Bioorg Med Chem Lett 17: 3599-3602.

WATERS NC AND EDSTEIN MD. 2012. In: Staines HM and Krishna S (Eds), Treatment and Prevention of Malaria. Antimalarial Drug Chemistry, Action and Use. London, United Kingdom. Springer Basel AG, p. 69-94.

WELLS S, DIAP G AND KIECHEL JR. 2013. The story of artesunate-mefloquine (ASMQ), innovative partnerships in drug development: case study. Malar J 12: 68.

WHO - WORLD HEALTH ORGANIZATION. 2015. Guidelines for the Treatment of Malaria. $3^{\text {rd }}$ ed., World Health Organization: Geneva, http://www.who.int/ malaria/publications/atoz/9789241549127/en/ Accessed: 21 September 2017.

WHO - WORLD HEALTH ORGANIZATION. 2016. World Malaria Report. http://www.who.int/malaria/publications/ world-malaria-report-2016/report/en/ Accessed: 21 September 2017.

WRIGHT CW, LINLEY PA, BRUN R, WITTLIN S AND HSU E. 2010. Ancient chinese methods are remarkably effective for the preparation of artemisinin-rich extracts of Qing Hao with potent antimalarial activity. Molecules 15: 804-812. 